\title{
Plan spawania stalowej kładki dla pieszych I
}

\section{Steel footbridge welding plan I}

\section{Streszczenie}

Opracowano plan spawania stalowej kładki dla pieszych. Omówiono w nim wymagania dotyczące materiałów podstawowych i dodatkowych do spawania, kwalifikacji spawaczy oraz stosowanych urządzeń spawalniczych. Przedstawiono ogólne wytyczne dotyczące spawania. Omówiono kolejność spawania detali oraz montażu gotowych segmentów. Przedstawiono wymagania dotyczące prostowania elementów oraz naprawy wadliwych odcinków spoin. Podano też zalecenia dotyczące próbnego montażu.

\section{Abstract}

The footbridge welding plan was presented. The standards from this field were quoted. The issues on parent and auxiliary materials, welders qualifications and weIding devices were described. What is more, the authors presented overall guidelines on welding technology and the sequence of welding of details and assembling segments. The requirements on straightening elements and repair of faulty joints were shown. There were given recommendations on test-assembly.

\section{Zakres stosowania}

Niniejszy plan technologiczny dotyczy spawania konstrukcji stalowej kładki dla pieszych. Główną konstrukcję stalową nośną kładki zaprojektowano jako dwa spawane dźwigary dwuteowe blachownicowe. Dźwigary połączone są ze sobą stężeniami poprzecznymi wy-



\section{Normy związane}

- PN-89/S-10050 - Obiekty mostowe - Konstrukcje stalowe - Wymagania i badania.

- PN-82/S-10052 - Obiekty mostowe - Konstrukcje stalowe - Projektowanie.

- PN-EN 10025 - Wyroby walcowane na gorąco z niestopowych stali konstrukcyjnych. Warunki techniczne dostawy.

- PN-EN 10204 - Wyroby metalowe. Rodzaje dokumentów kontroli.

- PN-EN 287-1 - Egzamin kwalifikacyjny spawaczy. Spawanie. Część 1: Stale.

- PN-EN 1418 - Personel spawalniczy. Egzaminowanie operatorów urządzeń spawalniczych oraz nastawiaczy zgrzewania oporowego dla w pełni zmechanizowanego i automatycznego spajania metali.

Dr hab. inż. Jacek Słania, prof. IS - Instytut Spawalnictwa, Gliwice.
- PN-EN ISO 14175 - Materiały dodatkowe do spawania. Gazy i mieszaniny gazów do spawania i procesów pokrewnych.

- PN-EN ISO 14341 - Materiały dodatkowe do spawania. Druty elektrodowe i stopiwo do spawania łukowego elektroda metalową w osłonie gazów stali niestopowych i drobnoziarnistych. Klasyfikacja.

- PN-EN 756 - Spawalnictwo. Materiały dodatkowe do spawania. Druty elektrodowe i kombinacje drut--topnik do spawania łukiem krytym stali niestopowych i drobnoziarnistych. Oznaczenia.

- PN-EN 760 - Materiały dodatkowe do spawania. Topniki do spawania łukiem krytym. Oznaczenia.

- PN-EN ISO 15609-1 - Specyfikacja i kwalifikowanie technologii spawania metali. Instrukcja technologiczna spawania. Część 1: Spawanie łukowe.

- PN-EN 970: 1999 + Ap1 - Spawalnictwo. Badania nieniszczące złączy spawanych. Badania wizualne.

- PN-EN 1714 + A1: 2005 Badania nieniszczące złączy spawanych. Badania ultradźwiękowe złączy spawanych.

- PN-EN 1712 + A1 + A2 - Badania nieniszczące złączy spawanych. Badania ultradźwiękowe złączy spawanych. Poziomy akceptacji.

- PN-EN ISO 17638 - Badania nieniszczące spoin. Badania magnetyczno-proszkowe.

- PN-EN ISO 23278 - Badania nieniszczące spoin. Badania magnetyczno-proszkowe spoin. Poziomy akceptacji. 
- PN-EN ISO 5817 - Spawanie. Złącza spawane ze stali, niklu, tytanu i ich stopów (z wyjątkiem spawanych wiązką). Poziomy jakości wg niezgodności spawalniczych.

- PN-EN ISO 9013 - Cięcie termiczne. Klasyfikacja cięcia termicznego. Specyfikacja geometrii wyrobu i tolerancje jakości.

- PN-EN ISO 9692-1 - Spawanie i procesy pokrewne. Zalecenia dotyczące przygotowania złączy. Część 1: Ręczne spawanie łukowe, spawanie łukowe elektrodą metalową w osłonie gazów, spawanie gazowe, spawanie metodą TIG i spawanie wiązką stali.

\section{Metody spawania}

Zastosowano następujące metody spawania:

- metodę 121 - spawanie łukiem krytym pod topnikiem,

- metodę 135 - spawanie elektrodą topliwą w osłonie mieszanki gazowej aktywnej.

\section{Materiały podstawowe}

Podłużne dźwigary dwuteowe zaprojektowane jako całkowicie spawane wykonano ze stali niestopowej S355J2G3 - wg PN-EN 10025.

Pozostałe elementy konstrukcji należy wykonać ze stali S235JRG2. Wymagane dokumenty kontroli wg PN-EN 10204:

- 3.2 - dla stali S355J2G3,

- 2.2 - dla stali S235JRG2.

\section{Materiały dodatkowe do spawania}

Do spawania konstrukcji kładki należy stosować materiały spawalnicze odpowiednie do użytych materiałów podstawowych i metod spawania.

Dla metody 121:

- drut spawalniczy ø3 mm - OK. Autrod 12.20 (ESAB) - klasyfikacja wg PN-EN 756: S2,

- topnik OK. Flux 10.71 (ESAB) - klasyfikacja wg PN-EN 760: SAAB 167 AC H5.

Dla metody 135:

- drut spawalniczy ø1,2 mm ULTRAMAG (LINCOLN) - klasyfikacja wg PN-EN ISO 14341: G3Si,

- mieszanka osłonowa $82 \% \mathrm{Ar}+18 \% \mathrm{CO}_{2}$ - klasyfikacja wg PN-EN ISO 14175: M21.

Dla materiałów spawalniczych wymagane są dokumenty kontroli 3.1 lub 2.2 wg PN-EN 10204.

\section{Kwalifikacje spawaczy}

Spawanie konstrukcji stalowej kładki należy powierzyć wykwalifikowanym spawaczom z aktualnymi uprawnienia wg PN-EN 287-1 (operatorom wg PN-EN 1418).

\section{Urządzenia do spawania}

Spawanie zmechanizowane łukiem krytym (metodą 121) powinno się wykonywać na urządzeniu ESAB.

Do spawania półautomatycznego metodą MAG (135) należy stosować półautomaty typu MAGSTER 501 i POWERTEC 500S.

Urządzenia spawalnicze muszą być w dobrym stanie technicznym.

\section{Przygotowanie materiału do spawania}

Elementy konstrukcyjne po ich wytrasowaniu zgodnie z rysunkami warsztatowymi należy ciąć mechanicznie lub gazowo za pomocą palników acetylenowo-tlenowych. Jakość brzegów ciętych i ukosowanych musi spełniać wymagania normy PN-EN ISO 9013 - klasa I. Krawędzie do spawania należy przygotowywać zgodnie z dokumentacją techniczną normą PN-EN ISO 9692-1 i instrukcjami technologicznymi spawania WPS. Powierzchnie na szerokości min. $20 \div 30 \mathrm{~mm}$ po obu stronach osi wzdłużnej spoiny powinny być przed spawaniem dokładnie oczyszczone z rdzy, zgorzeliny, tłuszczu, farby i innych zanieczyszczeń. Wilgotne powierzchnie trzeba osuszyć za pomocą palnika gazowego. Spoiny sczepne należy wykonywać metodą 135. Spawacze powinni posiadać aktualne uprawnienia. Minimalna długość spoin sczepnych powinna wy-

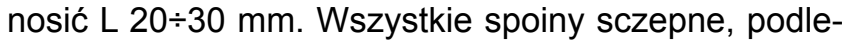
gają 100\% kontroli wizualnej. Spoiny sczepne niewtopione lub pęknięte muszą być bezwzględnie usunięte w całości przez szlifowanie i ułożone ponownie.

\section{Ogólne wytyczne dotyczące spawania}

- Proces spawania należy prowadzić zgodnie z planem i załączonymi do niego instrukcjami technologicznymi spawania WPS.

- Spawanie powinno się odbywać w temperaturze otoczenia nie mniejszej niż $+5^{\circ} \mathrm{C}$, na stanowiskach zabezpieczonych przed przeciągami.

- Na wszystkich złączach doczołowych należy stosować płytki wybiegowe, które powinny być tak samo przygotowane (ukosowane) jak materiał spawany.

- Poszczególne warstwy spoiny należy dokładnie oczyścić z żużla i odprysków przed ułożeniem warstwy następnej.

- Spoiny po wykonaniu muszą być ocechowane stemplem spawacza: przy spoinach krótkich na obu

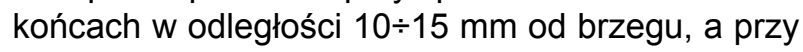
spoinach długich - co $1 \mathrm{~m}$.

- Należy prowadzić dziennik spawania. Za prowadzenie dziennika jest odpowiedzialny bezpośredni mistrz nadzorujący prace spawalnicze. 
- Nie wolno zajarzać łuku elektrycznego poza rowkiem spoiny. Niezamierzone przypadkowe ślady zajarzenia łuku na materiale muszą być usunięte przez szlifowanie i skontrolowane na obecność ewentualnych pęknięć.

\section{Naprawa wadliwych odcinków spoin}

Niedopuszczalne niezgodności spawalnicze należy usunąć zgodnie z obowiązującymi zasadami przy użyciu tych samych procedur jak dla spoin oryginalnych. Wycięty rowek powinien mieć min. 100 mm długości mierzonej na głębokości niezgodności, nawet jeżeli niezgodność jest mniejsza. Spoina naprawcza może być wykonana tylko dwukrotnie w tym samym obszarze.

Po spawaniu naprawczym całą spoinę należy poddać badaniom nieniszczącym jak dla wyspecyfikowanej spoiny oryginalnej oraz dodatkowo sprawdzić złącze w $100 \%$ metodą MT.

\section{Prostowanie po spawaniu}

Nadmiernie odkształcone elementy po spawaniu, niemieszczące się w granicach tolerancji wymiarowej, należy prostować.

Przy prostowaniu na gorąco należy przestrzegać następujących zasad:

- temperatura nagrzewania nie powinna przekraczać $650^{\circ} \mathrm{C}$,

- do nagrzewania można wykorzystać palniki gazowe acetylenowo-tlenowe z zastosowaniem miękkiego (neutralnego) płomienia nagrzewającego,

- chłodzenie elementów powinno odbywać się powoli, w temp. otoczenia nie niższej niż $5^{\circ} \mathrm{C}$, bez użycia wody,

- przy prostowaniu nie powinno się stosować metod udarowych.

\section{Kontrola i badania spoin}

Spoiny konstrukcji stalowej kładki wykonane w warunkach warsztatowych podlegają badaniom nieniszczącym według planu ujętego w tablicy I.

\section{Plan spawania}

\section{Wykonanie segmentów dwuteowych dźwigarów głównych}

Segmenty $\mathrm{S} 1 \div \mathrm{S} 7$ wchodzące w skład dźwigara należy wykonać w odbiciu lustrzanym.

\section{1) Segment $S 1$ - szt. $1+1$}

Podzespoły dwuteowe S1a i S1b należy składać i spawać na urządzeniu firmy ESAB do spawania łukiem krytym:

- spoiny 1 i 2 - wykonać wg WPS 1 ,

- prostować krzywizny,

- składać i spawać ze sobą podzespoły S1a i S1b (segment S1).

Kolejność spawania:

I. pasy - spoiny 3 i 4 - wg WPS 2 ,

II. środnik - spoina 5 - wg WPS 2;

- prostować krzywizny.

\section{2) Segment $S 2$ - szt. $1+1$}

Przekrój dwuteowy spawać na urządzeniu firmy ESAB do spawania łukiem krytym:

- spoiny nr 1 i 2 - wg WPS 1,

- prostować.

\section{3) Segment $\mathbf{S 3}$ - szt. $1+1$}

Podzespoły dwuteowe S3a i S3b spawać na urządzeniu firmy ESAB do spawania łukiem krytym:

- spoiny 1 i 2 - wg WPS 1 ,

- prostować krzywizny,

- składać ze sobą i spawać podzespoły S3a i S3b (segment S3).

Kolejność spawania:

I. pasy - spoiny 3 i 4 - według WPS 2,

II. środnik - spoina 5 - według WPS 2;

- prostować.

Uwaga: Naddatek $100 \mathrm{~mm}$ z prawej strony będzie usunięty w czasie próbnego montażu segmentów kładki.

\section{4) Segment S4 - szt. $1+1$}

Przekrój dwuteowy spawać na urządzeniu produkcji firmy ESAB do spawania łukiem krytym:

- spoiny 1 i 2 wg WPS 1.

5) Segmenty S5 - szt. $1+1$

Tablica I. Plan badań nieniszczących spoin wykonanych w warunkach warsztatowych

Table I. Non-destructive testing plan for joints made in workshop

\begin{tabular}{|c|c|c|c|c|}
\hline \multirow{2}{*}{ Opis złączy spawanych } & \multicolumn{3}{|c|}{ Rodzaj badań nieniszczących i ich zakres ${ }^{1)}$} & \multirow{2}{*}{$\begin{array}{l}\text { Poziom jako- } \\
\text { ści spoin }{ }^{2)}\end{array}$} \\
\hline & VT & UT & MT & \\
\hline Spoiny czołowe pasów i średników dźwigarów głównych & $100 \%$ & $100 \%$ & - & B \\
\hline Spoiny pachwinowe dźwigarów głównych & $100 \%$ & - & $5 \%$ & C \\
\hline $\begin{array}{l}\text { Pozostałe spoiny pachwinowe (przy tężnikach poprzecznych, } \\
\text { wiatrownicach, balustradach) }\end{array}$ & $100 \%$ & - & $2 \%$ & C \\
\hline
\end{tabular}




\section{6) Segmenty S6 - szt. $1+1$}

Przekroje dwuteowe spawać na urządzeniu firmy ESAB do spawania łukiem krytym:

- spoiny 1 i 2 - wg WPS 1.

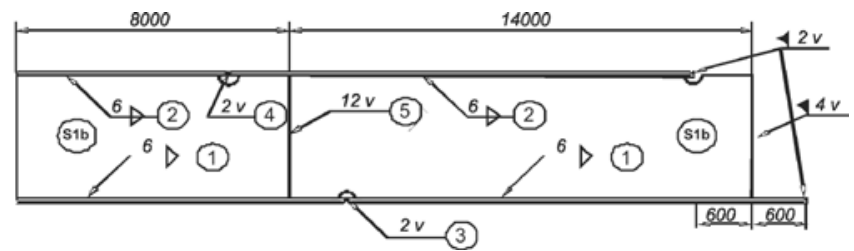

Rys. 1. Segment $\mathrm{S} 1$

Fig. 1. S1 segment

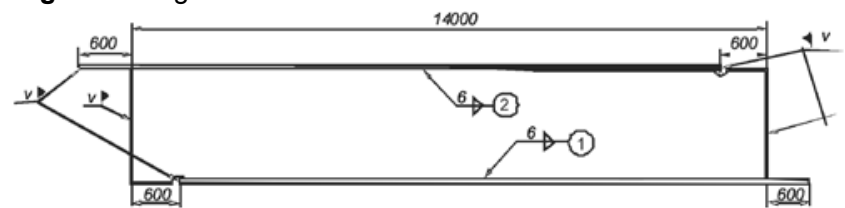

Rys. 2. Segment S2

Fig. 2. S2 segment

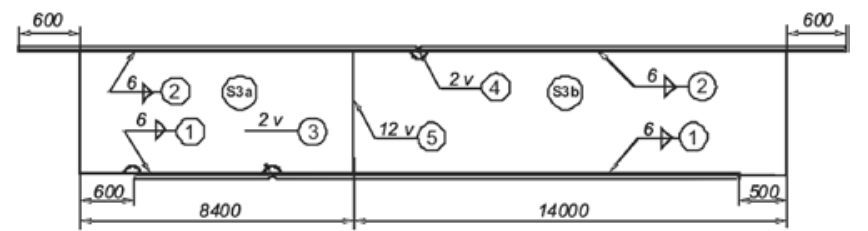

Rys. 3. Segment S3

Fig. 3. S3 segment

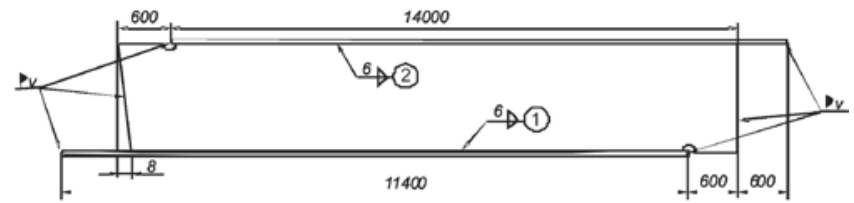

Rys. 4. Segment $\mathrm{S} 4$

Fig. 4. S4 segment

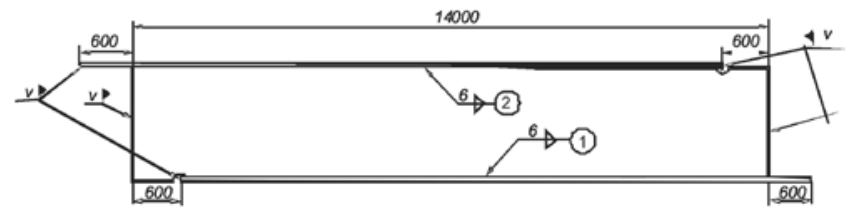

Rys. 5. Segment S5 i S6

Fig. 5. S5 and $\mathrm{S} 6$ segments

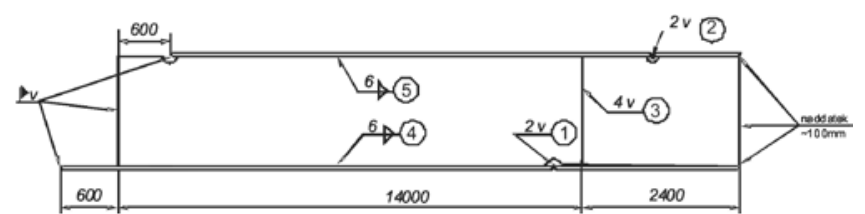

Rys. 6. Segment $S 7$

Fig. 6. S7 segment

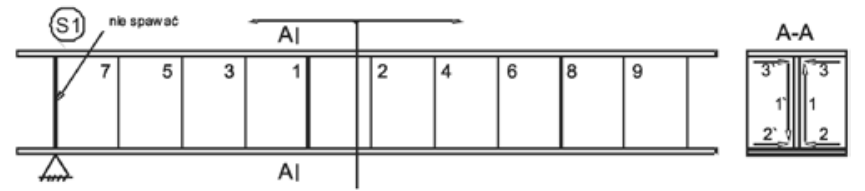

Rys. 7. Kolejność spawania

Fig. 7. Welding sequence

\section{7) Segment S7 - szt. $1+1$}

Składać i spawać pasy i środniki z dwóch części:

- spoiny 1,2 i 3 - wg WPS 2 ,

- prostować ewentualne krzywizny,

- przekrój dwuteowy spawać na urządzeniu firmy ESAB do spawania łukiem krytym: $s$

- poiny 4 i 5 - wg WPS 1 ,

- prostować.

Uwaga: Naddatek $\sim 100 \mathrm{~mm}$ z prawej strony będzie usunięty w czasie próbnego montażu segmentów kładki.

Montaż żeber poprzecznych do segmentów dwuteowych dźwigarów

- Trasować miejsca pod żebra poprzeczne według rysunków wykonawczych.

- Zakładać i sczepiać żebra do segmentów dwuteowych dźwigarów.

- Spawać żebra spoinami pachwinowymi dwustronnymi a $=4 \mathrm{~mm}$.

- Kolejność spawania - wg rys. 7 (od środka każdego segmentu w kierunku na zewnątrz elementu).

- Prostować krzywizny.

Uwaga: Nie spawać żeber występujących nad łożyskami podporowymi (w segmentach S1, S2, S4, S6, S7). Będą one spawane po próbnym zmontowaniu segmentów kładki i ustaleniu wymiarów między podporami.

\section{Montaż próbny konstrukcji stalowej kładki}

- Na wypoziomowanych leżniach wykonać szablon do składania w całość konstrukcji stalowej kładki w położeniu pracy.

- Dopuszcza się montaż próbny kładki w dwóch częściach na długości.

- Do zestawionych z segmentów dźwigarów dwuteowych zakładać i sczepiać poprzecznice dolne i górne wraz z zastrzałami oraz pręty stężenia wiatrowego.

- Spawać zgodnie z rysunkami warsztatowymi.

- Natrasować i upalić naddatki na długości kładki.

- Pasować do konstrukcji nośnej kładki elementy balustrady.

\section{Literatura}

[1] Kurpisz B.: Technologiczne plany spawania. Instytut Spawalnictwa, Gliwice 1991.

[2] Norma PN - EN ISO 3834-2: Wymagania jakości dotyczące spawania materiałów metalowych. Część 2: Pełne wymagania jakości.

[3] Norma PN - B - 06200: Konstrukcje stalowe budowlane. Warunki wykonania i odbioru. Wymagania podstawowe.

[4] Słania J.: Plan spawania carg płaszcza pieca obrotowego. Przegląd Spawalnictwa 2/2011, s. 36-41.

[5] Słania J., Wodecki D.: Plan spawania belki poprzecznej dźwigu. Przegląd Spawalnictwa 2/2011, s. 30-35.

[6] Słania J.: Plan technologiczny spawania płyty gąsienicowej. Przegląd Spawalnictwa 3/2010, s. 16-25. 